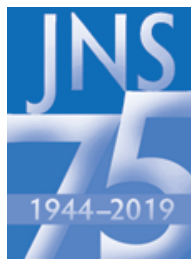

\title{
Current and future directions of deep brain stimulation for neurological and psychiatric disorders
}

\author{
JNSPG 75th Anniversary Invited Review Article
}

\author{
Darrin J. Lee, MD, PhD, ${ }^{1}$ Christopher S. Lozano, BSc, ${ }^{2}$ Robert F. Dallapiazza, MD, $\mathrm{PhD},{ }^{3}$ and \\ Andres M. Lozano, MD, PhD²
}

\begin{abstract}
1Department of Neurological Surgery, University of Southern California, Los Angeles, California; ${ }^{2 D e p a r t m e n t ~ o f ~}$ Neurological Surgery, University of Toronto, Ontario, Canada; and '3Department of Neurological Surgery, Tulane University, New Orleans, Louisiana
\end{abstract}

\begin{abstract}
Deep brain stimulation (DBS) has evolved considerably over the past 4 decades. Although it has primarily been used to treat movement disorders such as Parkinson's disease, essential tremor, and dystonia, recently it has been approved to treat obsessive-compulsive disorder and epilepsy. Novel potential indications in both neurological and psychiatric disorders are undergoing active study. There have been significant advances in DBS technology, including preoperative and intraoperative imaging, surgical approaches and techniques, and device improvements. In addition to providing significant clinical benefits and improving quality of life, DBS has also increased the understanding of human electrophysiology and network interactions. Despite the value of DBS, future developments should be aimed at developing less invasive techniques and attaining not just symptom improvement but curative disease modification.
\end{abstract}

https://thejns.org/doi/abs/10.3171/2019.4.JNS181761

KEYWORDS deep brain stimulation; Parkinson's disease; essential tremor; dystonia; epilepsy; functional neurosurgery

$\mathrm{D}$ EEP brain stimulation (DBS) is an FDA-approved treatment for Parkinson's disease (PD), essential tremor (ET), and dystonia. More recently, it has been approved for obsessive-compulsive disorder (OCD) and medically refractory epilepsy. DBS evolved from early surgical lesioning procedures. For instance, thalamotomy and pallidotomy were among the first treatments for PD in the 1950s, even prior to the advent of medical treatment such as dopamine replacement therapy. ${ }^{21,41,72} \mathrm{Al}$ though electrical stimulation was initially used to test for side effects prior to making a permanent lesion (e.g., thalamotomies), the first use of what is now considered modern DBS did not occur until 1980 with the use of midbrain and basal ganglia electrical stimulation to suppress intention tremor. ${ }^{14}$

Deep brain stimulation has a more favorable side-effect profile compared to lesioning procedures, and given the vast array of potential stimulation parameters, is highly adjustable. Moreover, for bilateral procedures, it has been shown to be safer than pallidotomies and thalamotomies in patients with PD. In addition to DBS being an effective clinical tool, it has also become an invaluable research tool. DBS surgery has led to a better understanding of basal ganglia circuitry as well as other neural networks. Intraoperative recordings enable both single-unit recordings of neurons as well as local field potentials of structures. Using these techniques, we are able to better understand circuit dynamics and interactions.

The advent of DBS has driven a renaissance of functional neurosurgery. It is estimated that more than 160,000 patients have received DBS, and the number of new patients treated worldwide is growing by more than 12,000

ABBREVIATIONS ACC = anterior cingulate cortex; $A D=$ Alzheimer's disease; $A D A S-C o g=$ Alzheimer's Disease Assessment Scale, Cognitive Subscale; $A$ LIC = anterior limb of the internal capsule; ANT = anterior nucleus of the thalamus; area LC = locus of the caudate neurons; BNST = bed nucleus of the stria terminalis; CMPfC = centromedian-parafascicular complex; DBS = deep brain stimulation; ET = essential tremor; GPi = globus pallidus pars interna; ITP = inferior thalamic peduncle; NAc = nucleus accumbens; $\mathrm{nbM}$ = nucleus basalis of Meynert; OCD = obsessive-compulsive disorder; PAG/PVG = periaqueductal gray/periventricular gray; PD = Parkinson's disease; PTSD = posttraumatic stress disorder; STN = subthalamic nucleus; VC/VS = ventral capsule/ventral striatum; Vim = ventral intermediate thalamic nucleus; VPL/VPM = ventral posterior lateral nucleus/ventral posterior medial nucleus.

SUBMITTED April 16, 2019. ACCEPTED April 18, 2019.

INCLUDE WHEN CITING DOI: 10.3171/2019.4.JNS181761. 


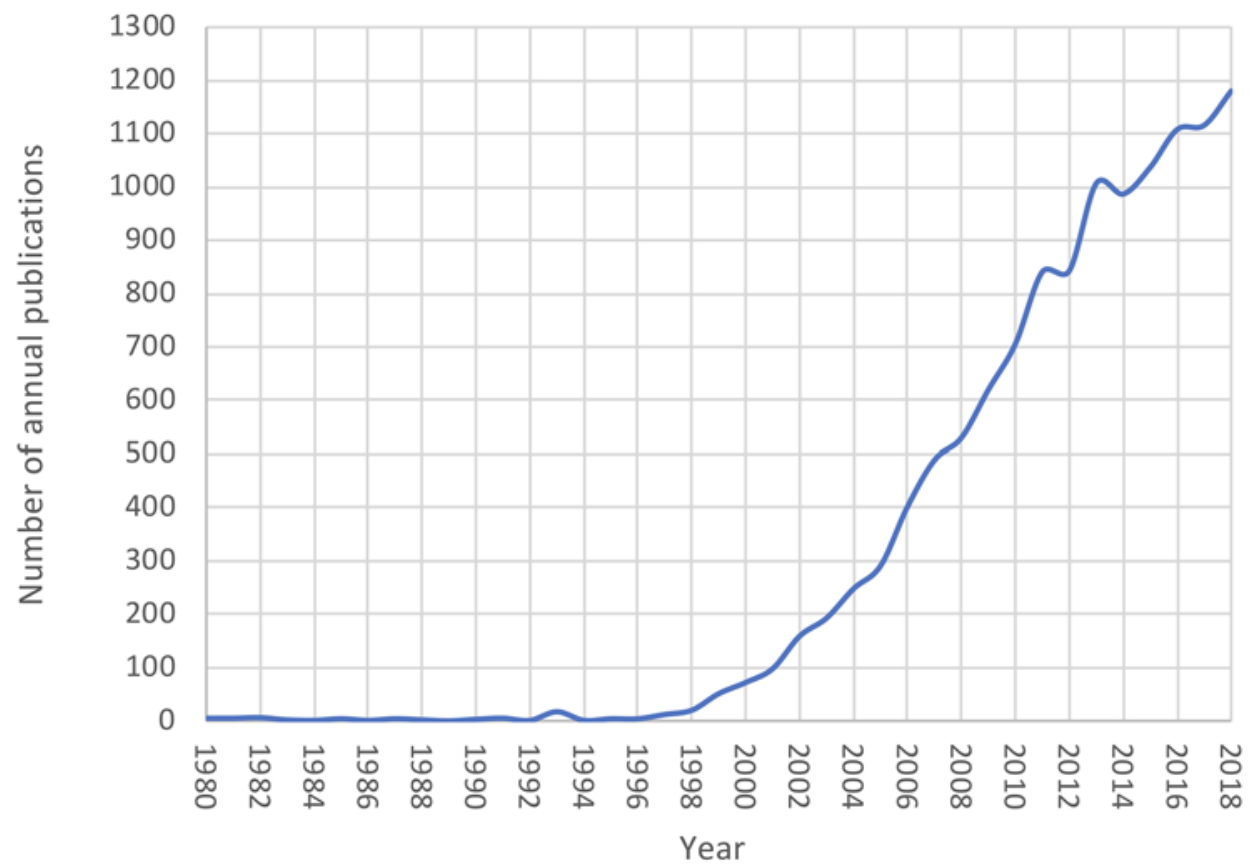

FIG. 1. Chart showing growth in the use of DBS. The figure shows the annual number of publications on DBS. These results were obtained by searching PubMed using the search term "Deep brain stimulation." Publications between 1980 and 2018 were tallied. Figure is available in color online only.

per year. The field of DBS is one of the fastest-growing areas in neurosurgery. One can measure the number of scientific manuscripts published per year to obtain an estimate of the activity in this field. As shown in Fig. 1, there was a relatively slow rise in activity in this field in the early 1980s when modern DBS surgery was introduced, with a sharp increase in the late 1990s with the adoption of thalamic DBS for tremor. The fastest rate of growth was in the 2005-2010 epoch following the approval of subthalamic and pallidal DBS for the treatment of PD. The yearto-year incremental growth was highest in 2012-2013, when the number of papers published increased from 843 by an additional 164 to reach 1007 . The number of DBS papers per year surpassed 1000 for the first time in 2013. The average growth per year for the last 5 years has decelerated from a baseline of approximately 1100 papers per year with a year-to-year growth of an additional 50 papers per year, down from the peak growth rate of more than 80 papers per year in the early part of this decade.

The clinical success of DBS treatment has paved the way for other forms of neuromodulation, including transcranial magnetic stimulation and focused ultrasound, and has led to increased interest in optogenetics, sonogenetics, and magnetogenetics. Over the past 40 years DBS techniques have been refined, and this has opened the door for developing DBS treatments beyond the movementdisorder realm, such as in pain, cognition, and psychiatric conditions.

\section{Proposed Mechanisms of Action}

Despite extensive basic science and human studies, the exact mechanism of DBS is still not entirely understood.
One overarching hypothesis is that electrical stimulation modulates abnormal circuits toward a more physiological state. ${ }^{29}$ At its most basic level, DBS is the application of electrical fields to stimulate neural elements-particularly axons around the electrode-resulting in opening and closing of voltage-gated sodium channels, generating action potentials and controlling the release of neurotransmitters; however, it is still unclear if this is entirely an inhibitory or excitatory mechanism or whether the effects are predominantly local or network-wide. There are 4 main mechanistic theories: 1) direct inhibition of neural activity, 2) direct excitation of neural activity, 3) information interruption, and 4) synaptic filtering.

The inhibition hypothesis suggests that DBS leads to inhibition of neural activity and follows from the observation that lesioning procedures, such as thalamotomies, pallidotomies, capsulotomies, and cingulotomies, have resulted in similar benefits in movement disorders and OCD. Moreover, there is often a lesional effect from the initial DBS electrode insertion that subsides over time. There is evidence that stimulation results in disrupted ionic, protein, cellular, and network levels, and results in a stable depolarization block that silences targeted cells; $;, 38$ however, data that argue against this consist of the fact that this block is not sustainable with continuous stimulation. ${ }^{2}$

Electrical stimulation can alter ionic balance by redistributing charged particles (e.g., $\mathrm{Na}^{+}$and $\mathrm{Cl}^{-}$ions) and subsequently inactivating voltage-gated currents ${ }^{8,28}$ as well as activating inhibitory afferents. ${ }^{11,19}$ Furthermore, there is evidence that DBS can uncouple neurons from their axons and cause a functional deafferentation from both efferent and afferent structures. ${ }^{27,68}$

In contrast, the excitation hypothesis suggests that DBS 
leads to direct excitation of neural activity. Electrical stimulation can cause antidromic excitation of afferent axons as well as excitation of efferent axons to the target nucleus and postsynaptic activity. ${ }^{68}$ This in turn could theoretically lead to an overall normalization of firing patterns, although the exact mechanisms are unclear.

The disruption hypothesis suggests that electrical stimulation blocks the information flow through the targeted brain structure. This theory is supported by the fact that DBS can result in inhibition of cortically evoked responses and spontaneous discharges. ${ }^{20}$ The synaptic filtering hypothesis posits that synapses will become low-pass filters of low-frequency signals. Thus, DBS could act by inhibiting the oscillatory activity within a given circuit. ${ }^{67}$ Whereas stimulated axons are able to fire at frequencies of approximately $100 \mathrm{~Hz}$, synaptic transmission is not able to occur at the same fidelity. ${ }^{15}$ Interestingly, there is evidence that high-frequency stimulation $(>100 \mathrm{~Hz}$ ) produces network changes that are different from low-frequency stimulation (1-10 Hz). Furthermore, neurotransmitter stores will deplete rapidly, and postsynaptic receptors will become depressed at a high frequency. ${ }^{76}$

Although current theories surrounding the mechanism of DBS are generally focused on immediate effects, there is evidence that DBS may lead to synaptic and neural plasticity. Furthermore, there is some evidence that suggests that DBS may lead to neurogenesis, synaptogenesis, and potentially neuroprotection. ${ }^{63}$ This is further supported by the fact that there are long-standing alterations in network activity that go beyond the target nucleus. However, at present there is no current evidence of a direct diseasemodifying effect. Remarkably, there are also effects on nonneuronal cells, like glial cells that can alter the surrounding neurochemical environment. ${ }^{62}$ Taken together, there is no clear consensus on the exact mechanism(s) of DBS, despite its clinical efficacy in multiple types of disorders. The most cogent opinion is that multiple mechanisms are at play.

\section{Current DBS Treatments}

\section{Approved Indications}

\section{Parkinson's Disease}

Deep brain stimulation for PD was approved by the FDA in 2002 and is the most common DBS procedure performed. It is primarily aimed at ameliorating the motor symptoms of PD, and has been shown to improve bradykinesia, tremor, rigidity, on-off fluctuations, and dyskinesias. However, its effects in treating gait disturbances, speech, and nonmotor problems such as cognitive dysfunction are less clear. The two most common DBS targets are the subthalamic nucleus (STN) and globus pallidus pars interna (GPi; Table 1). Randomized trials have demonstrated no significant difference in degree of motor improvement or complications between the two targets (with improvement in motor scores by $25 \%-60 \%$ ); however, targeting the STN can reduce the need for dopamine replacement medications by approximately $50 \%{ }^{16,24,44,87}$ STN DBS is not without a downside, as patients with DBS of the STN can exhibit decreases in visual motor processing speed and worsening depression scores compared to patients with DBS of the GPi. ${ }^{33}$
TABLE 1. Indications and targets for DBS in patients with neurological and psychiatric disorders

\begin{tabular}{|c|c|}
\hline Indication & Human Trial DBS Target \\
\hline \multirow[t]{5}{*}{ PD } & STN \\
\hline & GPi \\
\hline & Vim \\
\hline & PPN \\
\hline & $\mathrm{nbM}$ \\
\hline \multirow[t]{2}{*}{ ET } & Vim \\
\hline & $\mathrm{PSA} / \mathrm{cZI}$ \\
\hline \multirow[t]{2}{*}{ Dystonia } & GPi \\
\hline & STN \\
\hline \multirow[t]{7}{*}{ OCD } & VC/VS \\
\hline & NAc \\
\hline & BNST \\
\hline & STN \\
\hline & ITP \\
\hline & ALIC \\
\hline & Medial thalamus \\
\hline \multirow[t]{3}{*}{ Epilepsy } & ANT \\
\hline & CMPfc \\
\hline & Hippocampus \\
\hline \multirow[t]{5}{*}{ Tourette syndrome } & Dorsomedial thalamus \\
\hline & CMPfC \\
\hline & GPi (anteromedial, posteroventral) \\
\hline & ALIC \\
\hline & NAc \\
\hline \multirow[t]{7}{*}{ Major depressive disorder } & Subgenual cingulate gyrus \\
\hline & Habenula \\
\hline & Medial forebrain bundle \\
\hline & ITP \\
\hline & VC/VS \\
\hline & NAc \\
\hline & ALIC \\
\hline \multirow[t]{2}{*}{ Obesity } & Lateral hypothalamus \\
\hline & NAc \\
\hline \multirow[t]{4}{*}{ Anorexia nervosa } & Subgenual cingulate gyrus \\
\hline & NAc \\
\hline & VC/VS \\
\hline & BNST \\
\hline \multirow[t]{3}{*}{ Addiction } & NAc \\
\hline & STN \\
\hline & ALIC \\
\hline \multirow[t]{6}{*}{ Chronic pain } & PAG/PVG \\
\hline & VPL/VPM \\
\hline & ACC \\
\hline & CMPfC \\
\hline & VS \\
\hline & ALIC \\
\hline
\end{tabular}

CONTINUED ON PAGE $336 »$ 
» CONTINUED FROM PAGE 335

TABLE 1. Indications and targets for DBS in patients with neurological and psychiatric disorders

\begin{tabular}{cl}
\hline Indication & Human Trial DBS Target \\
\hline AD & Fornix \\
\hline & nbM \\
\hline & VC/VS \\
\hline Tinnitus & Area LC \\
\hline & STN \\
\hline PTSD & Vim \\
\hline Anxiety & Basolateral amygdala \\
\hline & ALIC \\
\hline & NAC \\
\hline
\end{tabular}

PPN = pedunculopontine nucleus; $P S A / c Z I=$ posterior subthalamic area/ caudal zona incerta.

In very select cases in which tremor is the dominant symptom, the ventral intermediate thalamic nucleus (Vim) has also been targeted because DBS of the Vim only alleviates the tremor symptoms. Although DBS currently is not beneficial for gait, speech, and nonmotor problems, there has been interest in targeting other locations in the brain to improve these symptoms. For instance, the pedunculopontine nucleus (PPN) has been targeted to improve gait symptoms, and the nucleus basalis of Meynert $(\mathrm{nbM})$ is currently being examined as a potential target to treat cognitive impairment. ${ }^{56,73}$

\section{Essential Tremor}

Essential tremor is the most common movement disorder in adults and is characterized by kinetic, intention, and/or postural tremor. ${ }^{59}$ The use of DBS for ET was first described in the 1980s and eventually approved by the US FDA in 1997, targeting the intranuclear Vim/ventral oral posterior nucleus (VOP), ventrolateral thalamus, and adjacent white matter tracts. ${ }^{92}$ The posterior subthalamic area/ caudal zona incerta (PSA/cZI) has also been targeted for ET. Numerous studies have demonstrated that unilateral Vim DBS is effective at reducing action tremor (53\%$63 \%$ tremor reduction). Bilateral Vim DBS has also been shown to be safe and achieves an even greater reduction in overall tremor (66\%-78\% tremor reduction), including axial, head/neck, and voice tremor. ${ }^{25}$

Not only has DBS improved patients' quality of life, but it has led to a better understanding of the underlying pathophysiology and electrophysiology of ET. Intraoperatively, it has been shown that Vim cells fire synchronously with the patient's tremor, and that electrical stimulation of these cells disrupts the tremor instantaneously.

\section{Dystonia}

Dystonia is a heterogeneous movement disorder characterized by sustained or intermittent muscle contractions leading to abnormal, repetitive movements and/or posturing. Bilateral GPi DBS has been used to treat medically refractory inherited or idiopathic segmental or generalized dystonia. To date, there have been more than 50 distinct studies evaluating the effects of DBS for dystonia.
This work has demonstrated a significant improvement in motor function, disability, and activities of daily living in both inherited and idiopathic dystonia as evidenced by multiple scales (Burke-Fahn-Marsden Dystonia Rating Scale and Toronto Western Spasmodic Torticollis Rating Scale). Overall, data suggest that there is on average a $65 \%$ reduction in symptoms with lasting effects..$^{70}$ As with PD and ET, the symptoms are often significantly reduced but not absent, with the opportunity for improvement.

\section{Obsessive-Compulsive Disorder}

Obsessive-compulsive disorder is characterized by chronic, persistent urges or thoughts that can lead to compulsions, and it affects approximately $2 \%$ of the population. ${ }^{9}$ It is thought to involve the cortico-striato-thalamocortical circuit. To date, OCD is the only FDA-approved psychiatric indication for DBS. More specifically, targeting the ventral capsule/ventral striatum (VC/VS) for medically refractory OCD was given a human device exemption in 2009. Since that time, other targets have been evaluated using the Yale-Brown Obsessive-Compulsive Scale (Y-BOCS), including the nucleus accumbens (NAc), bed nucleus of the stria terminalis (BNST), STN, anterior limb of the internal capsule (ALIC), and inferior thalamic peduncle (ITP). These treatments have elicited a significant improvement in Y-BOCS scores (> 30\% reduction), including obsessions and compulsions as well as improvements in social functioning. ${ }^{71}$

\section{Epilepsy}

In approximately $30 \%-40 \%$ of patients with epilepsy, the disorder is medically refractory to treatment. ${ }^{78}$ For those with medically refractory epilepsy, a subset of patients have surgical treatment options. The surgical treatment of epilepsy has primarily been with resective surgery; however, DBS has been used as a treatment strategy for patients who do not have an identifiable epileptic focus. The use of DBS for medically refractory epilepsy was first explored in the 1970s and 1980s with stimulation of the cerebellum and the anterior nucleus of the thalamus (ANT) ${ }^{22,23,84}$ Other areas have recently been identified as potential targets, including the centromedian-parafascicular complex (CMPfc) and the hippocampus. ${ }^{85}$

There have been 20 studies within the past 10 years that have been published on ANT DBS. The Stimulation of the Anterior Nucleus of the Thalamus for Epilepsy (SANTE) trial was the first randomized controlled trial targeting the ANT, which included 110 patients. This trial demonstrated a median $56 \%$ reduction in seizures at 2 years (54\% responder rate), ${ }^{32}$ with an increased reduction of $69 \%$ at 5 years (68\% responder rate).$^{77}$ Based on this level 1 evidence, the FDA recently approved ANT DBS for epilepsy. ${ }^{32}$

Although epilepsy is characterized by seizure frequency, duration, and severity, these patients often suffer from cognitive and behavioral deficits. As such, patients often undergo neuropsychological tests prior to any surgical intervention. There is evidence that DBS may in fact lead to improvement in executive function, depression, anxiety, attention, and mood. ${ }^{77,83}$ The underlying mechanism for cognitive improvement requires further study. 
Deep brain stimulation primarily uses continuous or "open loop" stimulation; however, there is increasing interest in developing "closed loop" stimulation treatment options to deliver stimulation based on electrographic biomarkers. With the advances in responsive neurostimulation, a recent trial has suggested that this personalized stimulation paradigm can be efficacious and safe as well. However, there have been no head-to-head trials between DBS and responsive neurostimulation for epilepsy.

\section{Other Psychiatric Disorders}

\section{Tourette Syndrome}

Tourette syndrome is a type of tic disorder that is characterized by involuntary repetitive movements and vocalizations. It is believed to be a disruption in the corticostriato-thalamo-cortical circuit. To date, there have been at least 150 reported cases of DBS for Tourette syndrome. ${ }^{4}$ Of these cases, approximately half of the patients received thalamic DBS (either dorsomedial or CMPfc), approximately $40 \%$ had pallidal DBS (anteromedial GPi, posteroventral GPi, or a combination of the two), and the rest were treated with DBS of either ALIC/NAc or STN. The median improvement in the Yale Global Tic Severity Scale score was greater than $50 \%$, suggesting a positive role in the treatment of Tourette syndrome.

\section{Major Depressive Disorder}

Because there is evidence for network alterations from DBS, there has been a significant interest in expanding DBS to other psychiatric disorders. There have been a number of studies evaluating DBS for depression in which variable efficacy was found. Several cortical and subcortical structures have been tested, including the subcallosal cingulate gyrus ( $\mathrm{Cg} 25)$, NAc, medial forebrain bundle, $\mathrm{VC} / \mathrm{VS}$, and ITP. The largest study to date was a randomized controlled trial evaluating the effects of DBS of the subcallosal cingulate gyrus; however, the results have not shown a significant antidepressant efficacy. ${ }^{45}$ Although DBS offers promising network changes and clinical outcomes, further work is necessary to identify the ideal target and stimulation parameters.

\section{Eating Disorders and Obesity}

Morbid obesity and anorexia nervosa can largely be considered as the opposite ends of the spectrum, with morbid obesity being defined as a body mass index $>40$ $\mathrm{kg} / \mathrm{m}^{2}$, and anorexia nervosa being defined as an exceedingly low body mass index $<18.5 \mathrm{~kg} / \mathrm{m}^{2}$ along with an unhealthy weight and body image. The underlying biology of eating and body image perception is quite complex, involving reward pathways (mesolimbic and mesocortical pathways), homeostasis mechanisms, and hunger/satiety centers. There have been a small number of DBS trials aimed at treating morbid obesity. These trials have targeted modulating motivation, volitional control, addiction, and feeding/satiety centers. The lateral hypothalamus has been evaluated as a potential DBS target because it is considered the feeding center. A few case series have suggested that lateral hypothalamic DBS results in weight loss: ${ }^{89}$ however, further studies are necessary to confirm these findings. The NAc has also been studied as a potential DBS target to reduce the reward of eating, with some success. ${ }^{40,61}$ Other theoretical targets include the medial and lateral orbitofrontal cortex, medial prefrontal cortex, ventral pallidum, caudate, insula, anterior cingulate cortex (ACC), amygdala, putamen, and hippocampus. ${ }^{55}$

Similar to other DBS indications, early evidence for DBS treatment originated from the benefits of lesioning procedures, such as leukotomy, ${ }^{65,69}$ thalamotomy, ${ }^{91}$ and capsulotomy for anorexia nervosa. ${ }^{6}$ Moreover, there is evidence for network dysfunction associated with selfawareness (insula, parietal cortex); visual and gustatory sensation (occipital cortex, insula); and the reward pathway (ventral striatum, ACC, subgenual cingulate cortex). To date, there have been a number of DBS studies for anorexia nervosa in which the subgenual cingulate cortex, ${ }^{57,58} \mathrm{NAc}^{88,90} \mathrm{VC} / \mathrm{VS},{ }^{64}$ and $\mathrm{BNST}{ }^{10}$ have been targeted, with promising but not definitive results.

\section{Substance Abuse/Addiction}

Addiction and substance abuse are significant societal problems. The use of DBS for addiction has largely been due to the beneficial side effects of DBS for other disorders, like OCD. As such, the primary targets have been the NAc and the STN. The complexity of these psychiatric disorders lends itself to multiple nodes in the circuit needing to be modulated at the same time. Consequently, there have been studies evaluating multiple concomitant targets (i.e., NAc and ALIC). ${ }^{17,48}$ Results have been promising with a reasonable safety profile, although further studies are necessary to determine efficacy.

\section{Chronic Pain}

Chronic pain affects approximately 5\%-19\% of the population; ${ }^{12,13}$ however, there are a number of different categories of pain (nociceptive vs deafferentation and central vs peripheral). Even prior to the first use of DBS for movement disorders, the first reported use of this technique for intractable pain syndromes occurred in the $1950 \mathrm{~s}{ }^{42}$ Although there are many types of chronic pain, previous pain indications include poststroke pain, phantom limb pain, brachial plexus injury, atypical facial pain, cephalgia, and spinal cord injury.

Similar to the PD and tremor literature, neuromodulation for relief of chronic pain was developed from lesioning procedures. Pain relief via cingulotomy $y^{5,34}$ suggested the ACC as a potential DBS target. There have been 3 primary DBS targets for pain, including the following: 1) the periaqueductal gray/periventricular gray (PAG/PVG), 2) sensory thalamus (i.e., ventral posterior lateral nucleus/ ventral posterior medial nucleus [VPL/VPM]), and 3) the ACC. Other targets include the CMPfc, VS/ALIC, and the posterior hypothalmus. ${ }^{35}$ There have also been studies with combined PAG/PVG and VPL/VPM stimulation in which investigators had inconclusive results. In addition to DBS, there has also been interest in using motor cortex stimulation to treat both poststroke and non-poststroke pain (facial neuropathic pain, phantom limb pain, postherpetic neuralgia, brachial plexus avulsion, Wallenberg syndrome, complex regional pain syndrome, multiple sclerosis-derived pain, spinal cord injury pain, and posttraumatic brain injury pain). ${ }^{66}$ 
The underlying pathophysiology of pain is quite intricate. As such, altering the underlying neural circuitry is exceedingly complex. In contrast to typical DBS stimulation parameters, the stimulation frequencies have typically been lower because DBS of the thalamus or PAG at lower frequencies $(<50 \mathrm{~Hz})$ is believed to cause analgesia, whereas higher frequencies $(>70 \mathrm{~Hz})$ result in hyperalgesia. ${ }^{30}$ However, even if one is able to lower pain intensity (i.e., visual analog scale scores), this does not always correlate to overall benefits in quality of life, ${ }^{1}$ further emphasizing the need to better understand the underlying neural circuitry and network interactions.

\section{Alzheimer's Disease}

Forniceal DBS. Alzheimer's disease (AD) is a neurodegenerative disease characterized by $\beta$-amyloid plaques, neuronal cell death, and neurofibrillary tangles with associated cognitive dysfunction. In particular, the most pervasive symptom of $\mathrm{AD}$ is cognitive and memory decline. Because medical treatment has only had limited success in treating $\mathrm{AD}$ symptoms, there has been increasing interest in other treatment modalities such as gene therapy ${ }^{74}$ and DBS. Recent evidence demonstrates disrupted network dysfunction, including the circuit of Papez, ${ }^{82}$ default mode network, ${ }^{36}$ and salience network. ${ }^{93}$ As such, the theory is that modulating these networks may improve cognition. The fornix is a white matter tract in the circuit of Papez that is critical for memory and cognition. Recently, there have been phase 1 and phase 2 clinical trials targeting forniceal DBS.

In a 6-patient phase 1 trial, half of the patients showed a slight worsening in the Alzheimer's Disease Assessment Scale, Cognitive Subscale (ADAS-Cog), whereas the other half appeared to demonstrate a mild improvement in ADAS-Cog scores. This led to a forniceal DBS phase 2 double-blind randomized controlled trial that demonstrated no significant difference between forniceal DBS and no stimulation. Interestingly, a subgroup analysis suggested that patients older than 65 years of age had less decline than patients who received sham stimulation, whereas those who were younger than 65 years of age had significantly worsening cognitive measures (ADAS-Cog and the Clinical Dementia Rating Scale Sum of Boxes [CDR-SB]). ${ }^{60}$ Based on these results, a phase 3 clinical trial is under way to evaluate the effects of forniceal DBS in patients older than 65 years of age.

Whereas the clinical effects of forniceal DBS remain unknown, forniceal DBS does activate a number of memory and cognition circuits. One year after continuous stimulation, there is increased activation of memory networks (fronto-temporo-parieto-striato-thalamic and fronto-temporo-parieto-occipito-hippocampal networks) and the default mode network..$^{54}$

$D B S$ of the $n b M$ and the VC/VS. Cholinergic innervation is important in mechanisms of learning and memory; however, there is also evidence for cholinergic neuronal loss in $\mathrm{AD}^{3}$ The $\mathrm{nbM}$ consists of cholinergic neurons within the basal forebrain that are important for working memory, but exhibit neuronal loss in AD. In a pilot study, 6 patients underwent bilateral nbM DBS for AD. In this tri- al, 4 of the 6 patients were responders (stable Mini-Mental State Examination and ADAS-Cog scores) ${ }^{49}$

Alzheimer's disease is also known to result in executive function decline. The VC/VS is involved in neural networks associated with executive function, including the dorsomedial and orbitofrontal cortices. A 3-patient pilot trial of DBS of the VC/VS was performed that demonstrated less cognitive decline compared to age-matched controls. Furthermore, VC/VS DBS resulted in frontal cortical activation. ${ }^{79}$ Both nbM and VC/VS DBS offer a safe and potentially efficacious treatment strategy, but require more supportive evidence.

\section{Tinnitus}

Tinnitus is the conscious perception of an auditory sensation without external stimuli. The auditory cortex and limbic pathways have been implicated in tinnitus pathophysiology. As such, neuromodulatory techniques have been used for the treatment of tinnitus. More specifically, transcranial magnetic stimulation has been used over the temporoparietal cortex to suppress its excitability. These findings led to trials in which DBS of Heschl's gyrus was used to treat tinnitus. There is also evidence to suggest that the Vim, locus of the caudate neurons (area LC), STN, amygdala, and hippocampus may modulate tinnitus. ${ }^{26,75}$

There have been a number of case reports in which patients received DBS for movement disorders, and concomitantly had subsequent improvement in their comorbid tinnitus with DBS of the STN and Vim. ${ }^{80,81}$ Similarly, there has been intraoperative evidence that tinnitus is reduced when an electrode lead passes through area LC..$^{18,51}$ The importance of area LC has been further elucidated in a case report of a unilateral vascular infarct in area LC reducing bilateral tinnitus..$^{52}$

\section{Posttraumatic Stress Disorder and Anxiety Disorder}

Posttraumatic stress disorder (PTSD) is characterized by a feeling of hopelessness, negative emotional states, and reactivity symptoms following a stressful event, and patients with PTSD often relive painful or traumatic memories. ${ }^{53}$ PTSD affects multiple cognitive and psychiatric domains, with evidence that the default mode network, salience network, ventral attention network, and affective network are all disrupted. ${ }^{47}$ As such, multiple forms of neuromodulation have been attempted to alleviate the symptoms of PTSD, including electroconvulsive therapy, transcranial magnetic stimulation, vagal nerve stimulation, and DBS. DBS for PTSD includes targeting the basolateral amygdala ${ }^{46}$ and, theoretically, stimulation of the subgenual cingulate gyrus. ${ }^{53}$ There has also been interest in DBS for anxiety based on improvements in symptoms during DBS of ALIC for OCD; however, DBS of the NAc was used for panic disorder in one patient, but the condition did not improve. ${ }^{50}$

\section{Complications}

Deep brain stimulation surgery carries inherent surgery-related risks and complications from treatment. The major surgical risk of DBS is intracerebral hemorrhage. The risk of intracerebral hemorrhage is approximately $1 \%-2 \%$ including minor hemorrhages. ${ }^{39,86}$ Seizures are a 
risk of any supratentorial procedure, and have a $1 \%$ incidence in DBS procedures. ${ }^{39}$ Medical complications including deep venous thrombosis, phlebitis, pneumonia, urinary tract infections, and pulmonary embolism, which may also occur with any surgical procedure and have been reported in less than $2 \%$ of DBS cases. The mortality rate from DBS is approximately $0.4 \%$, mostly related to postoperative myocardial infarction and pulmonary embolism.

Some risks are related directly to the DBS device. These can include lead migration and fracture $(2 \%-3 \%$ of the patients treated with DBS). Device infections have been reported in $3 \%-8 \%$ of the patients treated with these procedures. ${ }^{39}$ Side effects from electrical stimulation may occur as well, depending on the DBS target and anatomical location of the leads, and range from cranial nerve deficits and motor symptoms to psychiatric and autonomic perturbations.

\section{Technology Innovation}

The field of stereotactic and functional neurosurgery and DBS has been rapidly growing over the past 4 decades. Targeting specific nuclei or tracts has become more precise with advances in high-resolution imaging, including tractography and functional MRI. These developments in technology also include intraoperative imaging guidance and target confirmation.

There have also been technological advances in the device. The internal pulse generators (IPGs) have a battery life of approximately 4 years in typical PD patients. Furthermore, transcutaneous, rechargeable IPGs are available. With advancements in stimulation programming, it is important to be able to have multiple options. There is now the capability to have interleaving stimulation paradigms. Modern IPGs can now deliver programmed stimulation paradigms as well as store data recorded from the electrode leads themselves. Implanted recording devices have paved the way for further investigations regarding neurological diseases and underlying electrophysiological changes that occur in these states. Further understanding about the underlying biology will allow investigators to identify and correlate abnormal electrophysiology with behavior. This could lead to devices that deliver electrical stimulation based on abnormal EEG biomarkers in real time.

Deep brain stimulation electrodes have also become more advanced. The volume of tissue activation can be adjusted based on which contacts are stimulated simultaneously, thus affording programmers the ability to shape the electrical activity to certain parts of the target nuclei/tract. Some commercially available electrodes are capable of directional current delivery, and allow for adjustments to a particular targeted region. This advancement helps to optimize the stimulation paradigms and prevent unwanted side effects from DBS. In addition, whereas most DBS systems provide a constant train of electrical stimulations, there is increasing interest in closed-loop DBS in which stimulation is turned on based on detecting the appearance of a pathological physiological signal-such as the occurrence of an electroencephalographic abnormality in patients with epilepsy ${ }^{43}$ or the increase in oscillatory activity in patients with PD. ${ }^{31}$

Identifying the appropriate stimulation target or targets remains elusive. In various neurological and psychiatric disorders, identifying which circuits to activate or inhibit requires an in-depth understanding of the underlying network. As in epilepsy, there is currently interest in interrogating multiple nodes simultaneously through the use of stereotactic EEG for other disorders, which will potentially improve the understanding of these diseases. Because stereotactic EEG is an invasive modality, future noninvasive imaging techniques (e.g., magnetoencephalography, ultrasound) will be key to a better understanding of network physiology.

\section{Noninvasive DBS}

There is considerable interest in noninvasive neuromodulation for long-term treatment of neurological and psychiatric conditions. Currently, techniques like transcranial magnetic stimulation and focused ultrasound enable modulation of the brain; however, with less temporal resolution, anatomical specificity, and adaptability than DBS. There is now evidence for noninvasive neurostimulation using offsetting nonphysiological high-frequency stimulation (i.e., $2.00 \mathrm{kHz}$ and $2.01 \mathrm{kHz}$ ) to create focal subcortical lowfrequency stimulation at a specific target. ${ }^{37}$ Refinement of this technology could potentially avoid the complications from open surgery, such as infections and device failure. Although continuous stimulation may initially pose a problem, this technique could also be used as a noninvasive stimulation-mapping tool to guide lesioning or DBS treatment.

\section{Disease Modification}

Currently DBS is primarily aimed at treating disease symptoms as opposed to the underlying disease process. Although there is some evidence that DBS results in neuroprotection, future treatments should be aimed at treating the underlying disorder or circuit abnormality. Treatments such as gene therapy, immunotherapy, and cell transplantation have been explored in patients with PD; however, the clinical efficacy of these treatments has been equivocal.

Newer techniques have the opportunity to not only alter abnormal genetics, but also to modulate underlying aberrant circuitry in a more specific manner than DBS. For instance, optogenetics, magnetogenetics, and sonogenetics have the potential to revolutionize the field of neuromodulation from both a scientific standpoint and as a treatment paradigm. Optogenetics allows for manipulation of neuronal activity in a cell-type-specific fashion. Using this technique, it is possible to excite or inhibit specific cell types within a focal region. Similarly, magnetogenetics can be cell-type specific, but uses magnetoreceptors as opposed to light receptors to activate or inhibit the cells. Sonogenetics can use viral vector gene delivery to control the activity of certain cells, but at present does not have the temporal specificity of DBS or optogenetics.

Although certain diseases are associated with neurodegenerative processes, other disease processes are less clear. Further research needs to evaluate alterations in neural circuitry to understand the underlying mechanism. Because DBS affects both local and circuit-wide abnormalities, future neuromodulation should address those disruptions. These nuances further support the need for cell-type-spe- 
cific neuromodulation as opposed to general activation or inactivation of swaths of areas of the brain. For instance, the anatomical distribution of cells is not always well delineated. It is widely believed that the dorsolateral portion of the STN is the motor region of this structure, whereas the ventromedial subdivision is important in limbic and associative processes. However, there are multiple types of cells within each region, and stimulation of even a $1-\mathrm{mm}$ region may activate multiple types of cells. These newer techniques will potentially provide more refined granularity to neuromodulation and could have a profound clinical impact.

\section{Conclusions}

Deep brain stimulation is an effective treatment for a number of medically refractory disorders. Although the underlying mechanisms are not completely known, DBS has significantly improved the understanding of human physiology. In the past 4 decades there have been significant advances in technology and optimization as well as increasing interest in developing new indications for this treatment modality. Whereas DBS is primarily adjunctive in nature, future neuromodulation techniques should target disease modification and/or permanent alteration of abnormal circuitry.

\section{Acknowledgments} ship.

Dr. Lee was supported by the William P. Van Wagenen fellow-

\section{References}

1. Abreu V, Vaz R, Rebelo V, Rosas MJ, Chamadoira C, Gillies MJ, et al: Thalamic deep brain stimulation for neuropathic pain: efficacy at three years' follow-up. Neuromodulation 20:504-513, 2017

2. Ammari R, Bioulac B, Garcia L, Hammond C: The subthalamic nucleus becomes a generator of bursts in the dopamine-depleted state. Its high frequency stimulation dramatically weakens transmission to the globus pallidus. Front Syst Neurosci 5:43, 2011

3. Arendt T, Bigl V, Arendt A, Tennstedt A: Loss of neurons in the nucleus basalis of Meynert in Alzheimer's disease, paralysis agitans and Korsakoff's disease. Acta Neuropathol 61:101-108, 1983

4. Baldermann JC, Schüller T, Huys D, Becker I, Timmermann L, Jessen F, et al: Deep brain stimulation for Tourette-syndrome: a systematic review and meta-analysis. Brain Stimul 9:296-304, 2016

5. Ballantine HT Jr, Cassidy WL, Flanagan NB, Marino R Jr: Stereotaxic anterior cingulotomy for neuropsychiatric illness and intractable pain. J Neurosurg 26:488-495, 1967

6. Barbier J, Gabriëls L, van Laere K, Nuttin B: Successful anterior capsulotomy in comorbid anorexia nervosa and obsessive-compulsive disorder: case report. Neurosurgery 69:E745-E751, 2011

7. Benazzouz A, Hallett M: Mechanism of action of deep brain stimulation. Neurology 55 (12 Suppl 6):S13-S16, 2000

8. Beurrier C, Bioulac B, Audin J, Hammond C: High-frequency stimulation produces a transient blockade of voltage-gated currents in subthalamic neurons. J Neurophysiol 85:13511356,2001

9. Björgvinsson T, Hart J, Heffelfinger S: Obsessive-compulsive disorder: update on assessment and treatment. J Psychiatr Pract 13:362-372, 2007
10. Blomstedt P, Naesström M, Bodlund O: Deep brain stimulation in the bed nucleus of the stria terminalis and medial forebrain bundle in a patient with major depressive disorder and anorexia nervosa. Clin Case Rep 5:679-684, 2017

11. Boraud T, Bezard E, Bioulac B, Gross C: High frequency stimulation of the internal globus pallidus (GPi) simultaneously improves parkinsonian symptoms and reduces the firing frequency of GPi neurons in the MPTP-treated monkey. Neurosci Lett 215:17-20, 1996

12. Bouhassira D, Lantéri-Minet M, Attal N, Laurent B, Touboul C: Prevalence of chronic pain with neuropathic characteristics in the general population. Pain 136:380-387, 2008

13. Breivik H, Collett B, Ventafridda V, Cohen R, Gallacher D: Survey of chronic pain in Europe: prevalence, impact on daily life, and treatment. Eur J Pain 10:287-333, 2006

14. Brice J, McLellan L: Suppression of intention tremor by contingent deep-brain stimulation. Lancet 1:1221-1222, 1980

15. Bucher D, Goaillard JM: Beyond faithful conduction: shortterm dynamics, neuromodulation, and long-term regulation of spike propagation in the axon. Prog Neurobiol 94:307346, 2011

16. Castrioto A, Lozano AM, Poon YY, Lang AE, Fallis M, Moro E: Ten-year outcome of subthalamic stimulation in Parkinson disease: a blinded evaluation. Arch Neurol 68:1550-1556, 2011

17. Chen L, Li N, Ge S, Lozano AM, Lee DJ, Yang C, et al: Long-term results after deep brain stimulation of nucleus accumbens and the anterior limb of the internal capsule for preventing heroin relapse: an open-label pilot study. Brain Stimul 12:175-183, 2019

18. Cheung SW, Larson PS: Tinnitus modulation by deep brain stimulation in locus of caudate neurons (area LC). Neuroscience 169:1768-1778, 2010

19. Chiken S, Nambu A: High-frequency pallidal stimulation disrupts information flow through the pallidum by GABAergic inhibition. J Neurosci 33:2268-2280, 2013

20. Chiken S, Nambu A: Mechanism of deep brain stimulation: inhibition, excitation, or disruption? Neuroscientist 22:313322, 2016

21. Cooper IS: Chemopallidectomy: an investigative technique in geriatric parkinsonians. Science 121:217-218, 1955

22. Cooper IS, Amin I, Gilman S: The effect of chronic cerebellar stimulation upon epilepsy in man. Trans Am Neurol Assoc 98:192-196, 1973

23. Cooper IS, Amin I, Riklan M, Waltz JM, Poon TP: Chronic cerebellar stimulation in epilepsy. Clinical and anatomical studies. Arch Neurol 33:559-570, 1976

24. Dallapiazza RF, De Vloo P, Fomenko A, Lee DJ, Hamani C, Munhoz RP, et al: Considerations for patient and target selection in deep brain stimulation surgery for Parkinson's disease, in Stoker TB, Greenland JC (eds): Parkinson's Disease: Pathogenesis and Clinical Aspects. Brisbane: Codon Publications, 2018, pp 145-160

25. Dallapiazza RF, Lee DJ, De Vloo P, Fomenko A, Hamani C, Hodaie M, et al: Outcomes from stereotactic surgery for essential tremor. J Neurol Neurosurg Psychiatry 90:474-482, 2019

26. De Ridder D, Vanneste S, Menovsky T, Langguth B: Surgical brain modulation for tinnitus: the past, present and future. J Neurosurg Sci 56:323-340, 2012

27. Dejean C, Hyland B, Arbuthnott G: Cortical effects of subthalamic stimulation correlate with behavioral recovery from dopamine antagonist induced akinesia. Cereb Cortex 19:1055-1063, 2009

28. Do MT, Bean BP: Subthreshold sodium currents and pacemaking of subthalamic neurons: modulation by slow inactivation. Neuron 39:109-120, 2003

29. Dostrovsky JO, Lozano AM: Mechanisms of deep brain stimulation. Mov Disord 17 (Suppl 3):S63-S68, 2002 
30. Farrell SM, Green A, Aziz T: The current state of deep brain stimulation for chronic pain and its context in other forms of neuromodulation. Brain Sci 8:158, 2018

31. Feng XJ, Greenwald B, Rabitz H, Shea-Brown E, Kosut R: Toward closed-loop optimization of deep brain stimulation for Parkinson's disease: concepts and lessons from a computational model. J Neural Eng 4:L14-L21, 2007

32. Fisher R, Salanova V, Witt T, Worth R, Henry T, Gross R, et al: Electrical stimulation of the anterior nucleus of thalamus for treatment of refractory epilepsy. Epilepsia 51:899-908, 2010

33. Follett KA, Weaver FM, Stern M, Hur K, Harris CL, Luo P, et al: Pallidal versus subthalamic deep-brain stimulation for Parkinson's disease. N Engl J Med 362:2077-2091, 2010

34. Foltz EL, White LE Jr: Pain "relief" by frontal cingulumotomy. J Neurosurg 19:89-100, 1962

35. Frizon LA, Yamamoto EA, Nagel SJ, Simonson MT, Hogue O, Machado AG: Deep brain stimulation for pain in the modern era: a systematic review. Neurosurgery [epub ahead of print], 2019

36. Greicius MD, Srivastava G, Reiss AL, Menon V: Defaultmode network activity distinguishes Alzheimer's disease from healthy aging: evidence from functional MRI. Proc Natl Acad Sci U S A 101:4637-4642, 2004

37. Grossman N, Bono D, Dedic N, Kodandaramaiah SB, Rudenko A, Suk HJ, et al: Noninvasive deep brain stimulation via temporally interfering electric fields. Cell 169:1029-1041, 1041.e1-1041.e16, 2017

38. Hamani C, Florence G, Heinsen H, Plantinga BR, Temel Y, Uludag K, et al: Subthalamic nucleus deep brain stimulation: basic concepts and novel perspectives. eNeuro 4:e0140, 2017

39. Hamani C, Richter E, Schwalb JM, Lozano AM: Bilateral subthalamic nucleus stimulation for Parkinson's disease: a systematic review of the clinical literature. Neurosurgery 56:1313-1324, 2005

40. Harat M, Rudaś M, Zieliński P, Birska J, Sokal P: Nucleus accumbens stimulation in pathological obesity. Neurol Neurochir Pol 50:207-210, 2016

41. Hassler R, Riechert T: [Indications and localization of stereotactic brain operations.] Nervenarzt 25:441-447, 1954 (German)

42. Heath RG: Psychiatry. Annu Rev Med 5:223-236, 1954

43. Heck CN, King-Stephens D, Massey AD, Nair DR, Jobst BC, Barkley GL, et al: Two-year seizure reduction in adults with medically intractable partial onset epilepsy treated with responsive neurostimulation: final results of the RNS System Pivotal trial. Epilepsia 55:432-441, 2014

44. Herzog J, Volkmann J, Krack P, Kopper F, Pötter M, Lorenz $\mathrm{D}$, et al: Two-year follow-up of subthalamic deep brain stimulation in Parkinson's disease. Mov Disord 18:1332-1337, 2003

45. Holtzheimer PE, Husain MM, Lisanby SH, Taylor SF, Whitworth LA, McClintock S, et al: Subcallosal cingulate deep brain stimulation for treatment-resistant depression: a multisite, randomised, sham-controlled trial. Lancet Psychiatry 4:839-849, 2017

46. Koek RJ, Langevin JP, Krahl SE, Kosoyan HJ, Schwartz HN, Chen JW, et al: Deep brain stimulation of the basolateral amygdala for treatment-refractory combat post-traumatic stress disorder (PTSD): study protocol for a pilot randomized controlled trial with blinded, staggered onset of stimulation. Trials 15:356, 2014

47. Koek RJ, Roach J, Athanasiou N, van 't Wout-Frank M, Philip NS: Neuromodulatory treatments for post-traumatic stress disorder (PTSD). Prog Neuropsychopharmacol Biol Psychiatry 92:148-160, 2019

48. Kuhn J, Gründler TO, Bauer R, Huff W, Fischer AG, Lenartz $D$, et al: Successful deep brain stimulation of the nucleus accumbens in severe alcohol dependence is associated with changed performance monitoring. Addict Biol 16:620-623, 2011

49. Kuhn J, Hardenacke K, Lenartz D, Gruendler T, Ullsperger M, Bartsch C, et al: Deep brain stimulation of the nucleus basalis of Meynert in Alzheimer's dementia. Mol Psychiatry 20:353-360, 2015

50. Kuhn J, Lenartz D, Huff W, Lee S, Koulousakis A, Klosterkoetter J, et al: Remission of alcohol dependency following deep brain stimulation of the nucleus accumbens: valuable therapeutic implications? J Neurol Neurosurg Psychiatry 78:1152-1153, 2007

51. Larson PS, Cheung SW: Deep brain stimulation in area LC controllably triggers auditory phantom percepts. Neurosurgery 70:398-406, 2012

52. Larson PS, Cheung SW: A stroke of silence: tinnitus suppression following placement of a deep brain stimulation electrode with infarction in area LC. J Neurosurg 118:192-194, 2013

53. Lavano A, Guzzi G, Della Torre A, Lavano SM, Tiriolo R, Volpentesta G: DBS in treatment of post-traumatic stress disorder. Brain Sci 8:18, 2018

54. Laxton AW, Tang-Wai DF, McAndrews MP, Zumsteg D, Wennberg R, Keren R, et al: A phase I trial of deep brain stimulation of memory circuits in Alzheimer's disease. Ann Neurol 68:521-534, 2010

55. Lee DJ, Elias GJB, Lozano AM: Neuromodulation for the treatment of eating disorders and obesity. Ther Adv Psychopharmacol 8:73-92, 2018

56. Lee DJ, Milosevic L, Gramer R, Sasikumar S, Al-Ozzi TM, De Vloo P, et al: Nucleus basalis of Meynert neuronal activity in Parkinson's disease. J Neurosurg [epub ahead of print February 22, 2019. DOI: 10.3171/2018.11.JNS182386]

57. Lipsman N, Lam E, Volpini M, Sutandar K, Twose R, Giacobbe $\mathrm{P}$, et al: Deep brain stimulation of the subcallosal cingulate for treatment-refractory anorexia nervosa: 1 year follow-up of an open-label trial. Lancet Psychiatry 4:285-294, 2017

58. Lipsman N, Woodside DB, Giacobbe P, Hamani C, Carter JC, Norwood SJ, et al: Subcallosal cingulate deep brain stimulation for treatment-refractory anorexia nervosa: a phase 1 pilot trial. Lancet 381:1361-1370, 2013

59. Louis ED, Ferreira JJ: How common is the most common adult movement disorder? Update on the worldwide prevalence of essential tremor. Mov Disord 25:534-541, 2010

60. Lozano AM, Fosdick L, Chakravarty MM, Leoutsakos JM, Munro C, Oh E, et al: A phase II study of fornix deep brain stimulation in mild Alzheimer's disease. J Alzheimers Dis 54:777-787, 2016

61. Mantione M, van de Brink W, Schuurman PR, Denys D: Smoking cessation and weight loss after chronic deep brain stimulation of the nucleus accumbens: therapeutic and research implications: case report. Neurosurgery 66:E218, 2010

62. McIntyre CC, Anderson RW: Deep brain stimulation mechanisms: the control of network activity via neurochemistry modulation. J Neurochem 139 (Suppl 1):338-345, 2016

63. McKinnon C, Gros P, Lee DJ, Hamani C, Lozano AM, Kalia LV, et al: Deep brain stimulation: potential for neuroprotection. Ann Clin Transl Neurol 6:174-185, 2018

64. McLaughlin NC, Didie ER, Machado AG, Haber SN, Eskandar EN, Greenberg BD: Improvements in anorexia symptoms after deep brain stimulation for intractable obsessive-compulsive disorder. Biol Psychiatry 73:e29-e31, 2013

65. Mitchell-Heggs N, Kelly D, Richardson A: Stereotactic limbic leucotomy-a follow-up at 16 months. Br J Psychiatry 128:226-240, 1976

66. Monsalve GA: Motor cortex stimulation for facial chronic neuropathic pain: a review of the literature. Surg Neurol Int 3 (Suppl 4):S290-S311, 2012 
67. Montgomery EB Jr, Baker KB: Mechanisms of deep brain stimulation and future technical developments. Neurol Res 22:259-266, 2000

68. Moran A, Stein E, Tischler H, Belelovsky K, Bar-Gad I: Dynamic stereotypic responses of basal ganglia neurons to subthalamic nucleus high-frequency stimulation in the parkinsonian primate. Front Syst Neurosci 5:21, 2011

69. Morgan JF, Crisp AH: Use of leucotomy for intractable anorexia nervosa: a long-term follow-up study. Int J Eat Disord 27:249-258, 2000

70. Moro E, LeReun C, Krauss JK, Albanese A, Lin JP, Walleser Autiero S, et al: Efficacy of pallidal stimulation in isolated dystonia: a systematic review and meta-analysis. Eur J Neurol 24:552-560, 2017

71. Naesström M, Blomstedt P, Bodlund O: A systematic review of psychiatric indications for deep brain stimulation, with focus on major depressive and obsessive-compulsive disorder. Nord J Psychiatry 70:483-491, 2016

72. Narabayashi H, Okuma T: Procaine-oil blocking of the globus pallidus for the treatment of rigidity and tremor of parkinsonism. Proc Jpn Acad 29:134-137, 1953

73. Nombela C, Lozano A, Villanueva C, Barcia JA: Simultaneous stimulation of the globus pallidus interna and the nucleus basalis of Meynert in the Parkinson-dementia syndrome. Dement Geriatr Cogn Disord 47:19-28, 2019

74. Rafii MS, Baumann TL, Bakay RA, Ostrove JM, Siffert J, Fleisher AS, et al: A phase1 study of stereotactic gene delivery of AAV2-NGF for Alzheimer's disease. Alzheimers Dement 10:571-581, 2014

75. Rammo R, Ali R, Pabaney A, Seidman M, Schwalb J: Surgical neuromodulation of tinnitus: a review of current therapies and future applications. Neuromodulation [epub ahead of print], 2018

76. Rosenbaum R, Zimnik A, Zheng F, Turner RS, Alzheimer C, Doiron B, et al: Axonal and synaptic failure suppress the transfer of firing rate oscillations, synchrony and information during high frequency deep brain stimulation. Neurobiol Dis 62:86-99, 2014

77. Salanova V, Witt T, Worth R, Henry TR, Gross RE, Nazzaro $\mathrm{JM}$, et al: Long-term efficacy and safety of thalamic stimulation for drug-resistant partial epilepsy. Neurology 84:10171025,2015

78. Sander JW: The epidemiology of epilepsy revisited. Curr Opin Neurol 16:165-170, 2003

79. Scharre DW, Weichart E, Nielson D, Zhang J, Agrawal P, Sederberg PB, et al: Deep brain stimulation of frontal lobe networks to treat Alzheimer's disease. J Alzheimers Dis 62:621-633, 2018

80. Shi Y, Burchiel KJ, Anderson VC, Martin WH: Deep brain stimulation effects in patients with tinnitus. Otolaryngol Head Neck Surg 141:285-287, 2009

81. Smit JV, Janssen ML, Engelhard M, de Bie RM, Schuurman PR, Contarino MF, et al: The impact of deep brain stimulation on tinnitus. Surg Neurol Int 7 (Suppl 35):S848-S854, 2016

82. Sperling RA, Dickerson BC, Pihlajamaki M, Vannini P, LaViolette PS, Vitolo OV, et al: Functional alterations in memory networks in early Alzheimer's disease. Neuromolecular Med 12:27-43, 2010

83. Tröster AI, Meador KJ, Irwin CP, Fisher RS, SANTE Study Group: Memory and mood outcomes after anterior thalamic stimulation for refractory partial epilepsy. Seizure 45:133141,2017

84. Upton AR, Cooper IS, Springman M, Amin I: Suppression of seizures and psychosis of limbic system origin by chronic stimulation of anterior nucleus of the thalamus. Int $\mathbf{J}$ Neurol 19-20:223-230, 1985-1986

85. Velasco F, Velasco AL, Velasco M, Jiménez F, Carrillo-Ruiz JD, Castro G: Deep brain stimulation for treatment of the epilepsies: the centromedian thalamic target. Acta Neurochir Suppl 97:337-342, 2007

86. Videnovic A, Metman LV: Deep brain stimulation for Parkinson's disease: prevalence of adverse events and need for standardized reporting. Mov Disord 23:343-349, 2008

87. Volkmann J, Allert N, Voges J, Sturm V, Schnitzler A, Freund HJ: Long-term results of bilateral pallidal stimulation in Parkinson's disease. Ann Neurol 55:871-875, 2004

88. Wang J, Chang C, Geng N, Wang X, Gao G: Treatment of intractable anorexia nervosa with inactivation of the nucleus accumbens using stereotactic surgery. Stereotact Funct Neurosurg 91:364-372, 2013

89. Whiting DM, Tomycz ND, Bailes J, de Jonge L, Lecoultre V, Wilent B, et al: Lateral hypothalamic area deep brain stimulation for refractory obesity: a pilot study with preliminary data on safety, body weight, and energy metabolism. J Neurosurg 119:56-63, 2013

90. Wu H, Van Dyck-Lippens PJ, Santegoeds R, van Kuyck K, Gabriels L, Lin G, et al: Deep-brain stimulation for anorexia nervosa. World Neurosurg 80:S29.e1-S29.e10, 2013

91. Zamboni R, Larach V, Poblete M, Mancini R, Mancini H, Charlin V, et al: Dorsomedial thalamotomy as a treatment for terminal anorexia: a report of two cases. Acta Neurochir Suppl (Wien) 58:34-35, 1993

92. Zesiewicz TA, Elble R, Louis ED, Hauser RA, Sullivan KL, Dewey RB Jr, et al: Practice parameter: therapies for essential tremor: report of the Quality Standards Subcommittee of the American Academy of Neurology. Neurology 64:20082020,2005

93. Zhou J, Greicius MD, Gennatas ED, Growdon ME, Jang JY, Rabinovici GD, et al: Divergent network connectivity changes in behavioural variant frontotemporal dementia and Alzheimer's disease. Brain 133:1352-1367, 2010

\section{Disclosures}

Dr. Lozano has received consultancies from Medtronic, St. Jude, Boston Scientific, and Insightec, and is a cofounder of Functional Neuromodulation, Ltd.

\section{Author Contributions}

Conception and design: Lee. Drafting the article: Lee. Critically revising the article: AM Lozano, CS Lozano, Dallapiazza. Reviewed submitted version of manuscript: all authors. Approved the final version of the manuscript on behalf of all authors: AM Lozano.

\section{Correspondence}

Andres M. Lozano: University of Toronto, Toronto, ON, Canada. andres.lozano@uhnresearch.ca. 